\title{
En el camino de la contingencia. Montaigne y el fundamento místico de la ley
}

Manuel Tirziani*

Resumen: La noción de Ley -del mismo modo que las nociones de Estado o de Nación - no es sino una entelequia que enmascara tras de sí una ausencia sustancial. Su existencia no posee otro objetivo que el de brindar un sostén simbólico capaz de velar ese vacío originario, haciendo de nuestro mundo un lugar menos acosado por la incertidumbre. De acuerdo con esto, el objetivo del presente trabajo es el de internarnos en una búsqueda que pueda conducirnos nuevamente hacia ese suelo originario, hacia ese momento cero de la institución. El ensayista Michel de Montaigne oficiará de guía en esa búsqueda. Él nos conducirá hacia el terreno en el cual la solidez de los fundamentos parece desvanecerse, o, más bien, hacia el momento simbólico en el cual una mera decisión humana, tan arbitraria como contingente, da origen a aquellas normas que poco a poco, gracias a esa maestra violenta y traidora que es la costumbre, habrán de ser veneradas en su aparente intemporalidad.

Palabras clave: Montaigne, ley, escepticismo, contingencia, fundamento místico.

Abstract: The notion of law -as the notions of state or nation- is nothing but an entelechy that masks behind it a substantial absence. Its existence has no other purpose than to provide us with a symbolic support able to veil that originating void, making our world a place less hurried by uncertainty. In accordance with this, the aim of the present paper is to begin a search that may lead us back to the original soil, to the time zero of institution. The essayist Michel de Montaigne will be our guide. He will lead us to the land on which the strength of the foundation seems to vanish, or, rather, to the symbolic moment in which a mere humane, arbitrary and contingent decision gives rise to those standards who gradually, thanks to the violent and treacherous teacher who is custom, start to be worshiped in his apparent timelessness.

Keywords: Montaigne, law, scepticism, contingency, mystical foundation.

\footnotetext{
* Licenciado en Filosofía por la Universidad Nacional del Litoral. Actualmente es Becario de Postgrado del CONICET y se encuentra finalizando sus estudios de Doctorado en la Universidad de Buenos Aires, con una tesis titulada "Ante el desafío de vivir con otros. Controversias en la prehistoria de la tolerancia moderna: Castellion, Bodin, Montaigne”. Dirección electrónica: manueltizziani@gmail.com
} 
¿Un dios o un hombre, ob extranjeros, ha sido la causa de vuestra legislación?

Platón, Leyes

¿Qué verdad es la que limitan estas montañas, la que es mentira en el mundo que hay al otro lado?

Montaigne, Ensayos

Las ideas de Ley o Estado, al igual que la de Nación, no son sino, en última instancia, modos diversos de rodear, sin nunca abarcar, ese núcleo inasible de irracionalidad que yace por debajo de todo ordenamiento institucional, tratar-siempre en forma precaria- de llenar simbólicamente aquel vacio originario constitutivo, buscando dotar de sentido, volver inteligible (y soportable) un universo que, una vez privado de toda garantía trascendente, no puede evitar eventualmente confrontarse a la radical contingencia de sus fundamentos.

Elías Palti, La nación como problema

\section{Fundamentos desfundados}

La noción de Ley -del mismo modo en que las nociones de Estado o de Nación, tal cual nos sugiere Elías Palti en uno de los pasajes que citamos arriba ${ }^{1}$ - no es sino una entelequia que enmascara tras de sí una ausencia sustancial; una manifestación sustentada y legitimada tan sólo, dirá Michel de Montaigne (1533-1592), por " $a$ | la barba cana y las arrugas del uso que la acompañan". ${ }^{2}$ Su existencia no posee otro objetivo que el de brindar un

\footnotetext{
${ }^{1}$ Palti, Elías, La nación como problema, Buenos Aires, Fondo de Cultura Económica, 2006, p.145-146.

2 Montaigne, Michel de, Los ensayos, Barcelona, Acantilado, 2007, I, 22, p.141. Los ensayos son sido citados de acuerdo a la traducción realizada y editada por Jordi Bayod Brau. También se ha consultado la reciente edición francesa a cargo de Emmanuel Naya, Delphine Reguig-Naya y Alexandre Tarrête (París, Gallimard Folio Classique, 2009, 3 vols.), en base a la cual se han introducido algunas mínimas modificación de traducción. Por otra parte, las letras que preceden al texto $\left(a, a^{2}, b, c\right)$ corresponden a cada una de las ediciones originales de la obra, a saber: $a\left|1580, a^{2}\right| 1582, b \mid 1588$ y $c \mid 1595$. El número de libro ha sido consignado en numeración romana, mientras que cada uno de los capítulos lo ha sido en numeración arábiga, seguido del número
} 
sostén simbólico capaz de velar ese vacío originario, haciendo de nuestro mundo un lugar menos acosado por la incertidumbre.

Dicho esto, señalamos que el objetivo que nos proponemos en este trabajo no es otro que de internarnos en una búsqueda que pueda conducirnos nuevamente hacia ese suelo originario, hacia ese momento cero de la institución. Y dado que nos resultaría imposible alcanzar dicha meta por nuestro propio esfuerzo, hemos elegido secundar en la tarea a alguien que, desde nuestra perspectiva, ha recorrido ese camino con elocuente claridad. Será el ensayista Michel de Montaigne quien oficiará de guía; él nos conducirá hacia el terreno en el cual la solidez del fundamento parece desvanecerse. O, más bien, hacia el momento simbólico en el cual una mera decisión humana, tan arbitraria como contingente, da origen a aquellas normas que poco a poco, gracias a esa maestra violenta y traidora que es la costumbre, habrán de ser veneradas en su aparente intemporalidad.

Nuestro recorrido será el siguiente: en primer lugar reconstruiremos los argumentos de Montaigne en relación con la fuerza de la costumbre, pues esas reflexiones nos conducirán sin mayores rodeos hacia el pantanoso terreno de las normas legales. Luego de esas reflexiones iniciales, seguiremos desandando el camino que Montaigne nos propone, intentando sacar a la luz la agudeza de la actitud desmitificadora que encarna el ensayista. Una actitud que podría ser extendida hacia el atrás y hacia adelante, hacia el pasado y hacia el futuro: hacia el pasado, en tanto ella parece encontrar sus orígenes las Hipotiposis Pirrónicas de Sexto Empírico; hacia el futuro, en la medida en que esa actitud de desmitificación nos revela que toda institución humana no se sustenta más que en un acto arbitrario y contingente, en una simple decisión. Será Blaise Pascal (1623-1662), asiduo lector de Montaigne, el primero de los pensadores modernos en acusar el impacto de las reflexiones de éste. Y en nuestros días, será Jacques Derrida (19302004) quien retomará, desde la perspectiva de la deconstrucción, aquellas primeras consideraciones. Abocado al desmantelamiento del concepto de ley, y vinculándolo directamente con el poder y la violencia, Derrida nos recordará la vigencia y actualidad de los argumentos que Montaigne nos entrega en sus Ensayos.

de página correspondiente a la edición castellana antes mencionada. 


\section{Esa maestra violenta y traidora}

La costumbre, noción central en muchas de las argumentaciones que Montaigne elabora a lo largo de sus Ensayos, ${ }^{3}$ es caracterizada como una suerte de fuerza inercial a la que los seres humanos se ven sometidos a cada instante, y cuya autoridad -forjada sigilosamente desde las sombras-, una vez establecida, se hace casi imposible de contrarrestar:

a| [L]a costumbre es en verdad una maestra violenta y traidora. Establece en nosotros poco a poco, a hurtadillas, el pie de su autoridad; pero, por medio de este suave y humilde inicio, una vez asentada e implantada con la ayuda del tiempo, nos descubre luego un rostro furioso y tiránico, contra el cual no nos resta siquiera la libertad de alzar los ojos ${ }^{4}$.

Montaigne recoge aquí una tradición ancestral -posible de remontar hasta Demócrito- que llega hasta sus manos gracias a su amigo Étienne de

\footnotetext{
3 "La noción de costumbre es central en los Ensayos, donde aparece como una tiránica fuerza nacida de la debilidad del ser humano: la mera repetición de determinados actos a lo largo del tiempo les otorga una especie de fuerza inercial, que obliga al sujeto a perpetuarlos indefinidamente. La fuerza de la costumbre explica por qué el hombre, a pesar de ser voluble e inestable, no puede permanecer constantemente en un estado heraclíteo de indefinición: es su propio carácter imperfecto y su impotencia lo que le confiere una figura determinada, impidiendo que vague toda su vida entre las formas más diversas." (Navarro Reyes, Jesús, La extrañeza de sí mismo, Sevilla, Fénix Editora, 2005, p.169). Más allá de la indiscutible potencia de esta fuerza inercial, también se ha señalado con justeza que "Montaigne tiene ciertas dificultades para decidir hasta dónde llega el poder de la costumbre: ¿es todo costumbre, incluidos los fundamentos de la moral, las reglas de la razón, los principios de comportamiento humano? ¿O es que existe un fondo universal, una naturaleza humana que las costumbres eventualmente esconden, pero que no modifican?" (Todorov, Tzvetan, Nosotros y los otros, México, Siglo XXI, 1991, p.53). Compartimos esta observación de Todorov pues, como hemos podido considerar a partir de nuestro propio estudio de la obra de Montaigne, éste fluctúa entre las dos posiciones antes mencionadas, es decir, entre la defensa de una razón natural incorruptible más allá de la costumbre, y la inexistencia de leyes naturales. Esa misma fluctuación convierte a la cuestión casi en un indecidible. Al respecto, véase Los ensayos, II, 12, pp. 874-875.

${ }^{4}$ Los ensayos. I, 22, p. 127.
} 
la Boétie (1530-1563), quien algunos años antes había detallado con claridad el rigor que es capaz de revelar esta reina y emperatriz del mundo. En su Discurso de la servidumbre voluntaria (1553), La Boétie lleva adelante una crítica radical de la dominación política, sea cual sea su manifestación empírica, y devela las razones últimas sobre las que se cimienta ese vicio innombrable que implica el consentir voluntariamente la esclavitud. Luego de pronunciarse a favor de la existencia de un derecho natural a la libertad, La Boétie arriba a la conclusión de que los seres humanos son capaces de subvertir sin mayores dificultades su prístina forma de ser, y de amoldarse cómodamente al yugo de la sujeción, gracias a la costumbre, a ese impulso inercial que tiene la potencia de trastocar incluso a la propia naturaleza.

$[\mathrm{L}] \mathrm{a}$ costumbre, que en todas las cosas ejerce un poder tan grande sobre nuestras acciones, tiene en particular el poder de enseñarnos a servir; es ese poder el que a la larga (como se cuenta de Mitrídates, quien terminó por habituarse al veneno) nos hace consentir sin repugnancia la amarga ponzoña de la servidumbre (...) Las semillas que la naturaleza pone en nosotros son tan delicadas y tan frágiles que no pueden resistir el menor choque de pasiones ni la influencia de una educación que se les opone $e^{5}$.

Es esta misma idea la que reaparece en el capítulo titulado "La costumbre y el no cambiar fácilmente una ley aceptada" (I, 22), en donde Montaigne reconoce, como veíamos hace un momento, la potencia casi absoluta que los hábitos adquieren sobre la vida humana y sus diversas maneras de existir. Los sujetos, afirma, se hallan aprisionados por estos modos de ser que han ido incorporando desde su más tierna infancia, y su capacidad de actuar más allá de los estrechos márgenes que establecen los hábitos de la caverna se entorpece considerablemente. ${ }^{6}$ Más aún, la inmensa mayoría no sólo se ve compelido a actuar de un modo determinado, sino

\footnotetext{
${ }^{5}$ La Boétie, Étienne, Discurso de la servidumbre voluntaria, Buenos Aires, Las cuarenta, 2010, p. 36. Algunos años más tarde, Pierre Charron, el más importante discípulo de Montaigne, afirmará lo siguiente: "Pero ¿quién creería lo grande e imperiosa que es la autoridad de la costumbre? El que ha dicho que es otra naturaleza no lo ha expresado lo suficiente, pues hace más que la naturaleza, combate la naturaleza" (Charron, Pierre, De la sabiduría, Buenos Aires, Losada, 1948, II, 8, p. 330).

${ }^{6}$ La referencia a Platón, y a su famosa alegoría, es explícita: “ $a \mid$ Creo, al respecto, $c \mid$ en la caverna de Platón en su República”, afirma Montaigne (Los ensayos, I, 22, p. 127).
} 
que incluso se torna incapaz de detenerse a reflexionar acerca de esa particular forma de existir, o de poner en entredicho aquellos mandatos ancestrales de la costumbre. " $a \mid$ El principal efecto de su poder es sujetarnos y aferrarnos hasta el extremo de que apenas seamos capaces de librarnos de su aprisionamiento, y de entrar en nosotros mismos para discurrir y razonar acerca de sus mandatos". ${ }^{7}$ Los sujetos se hallan fuera de sí, exiliados de su propio juicio; han caído presa de la opinio communis, perdiendo su autonomía tanto en el campo del pensamiento como en el de la acción: “ $a \mid$ Las comunes figuraciones que encontramos revestidas de autoridad a nuestro alrededor, e infundidas en nuestra alma por la semilla de nuestros padres, parece que fuesen las naturales y generales", 8 afirma Montaigne. Del mismo modo en que los vasallos de La Boétie consideran que es natural doblar sus rodillas ante el tirano por haber sido criados para ello, los hombres del ensayista tienen enormes dificultades para trasponer las barreras de los hábitos, y para comprender que las opiniones, costumbres y leyes que sus padres les han trasmitido distan de tener un fundamento natural e incontrovertible. De ahí, de esa ceguera, procede que todos -o casi- estén satisfehos de habitar en el lugar en el que lo hacen. ${ }^{9}$ De ahí procede, también, el hecho

\footnotetext{
${ }^{7}$ Los ensayos. I, 22, p. 138.

${ }^{8}$ Los ensayos. I, 22, p. 139. El subrayado es nuestro.

9 “c| Gracias a la costumbre todo el mundo está satisfecho del lugar donde la naturaleza lo ha fijado." (Los ensayos. I, 22, p. 139). Moderamos nuestra afirmación con un "casi", pues, como nos lo dirá el propio Montaigne, existe un número reducido de individuos - los sabios, u hombres de entendimiento- que realiza un esfuerzo constante por mantenerse consciente de la arbitrariedad de sus costumbres, intentando de ese modo salvaguardar la libertad de su juicio: " $a \mid[\mathrm{E}] \mathrm{l}$ sabio debe por dentro separar su alma de la multitud, y mantenerla libre y capaz de juzgar libremente las cosas." Los ensayos. I, 22, p.143. Puede decirse que esta idea, según la cual existe $-\mathrm{O}$ al menos puede existir- un grupo de hombres selectos que tienen la capacidad de mirar más allá que el común de la gente, es otra de las que Montaigne parece deber a Étienne de la Boétie, quien en su Discurso afirmaba lo siguiente: "Pero siempre habrá algunos que, más audaces e inspirados que los demás, sienten el peso del yugo y no puede dejar de sacudírselo; algunos que no se habitúan nunca al sometimiento y siempre y sin cesar (al igual que Ulises buscando por tierra y por mar volver a ver el humo de su casa) recuerdan sus derechos naturales y están prestos a reivindicarlos en todas las ocasiones. Ellos tienen puro el entendimiento y clarividente el espíritu; no se conforman, como los ignorantes embrutecidos, con
} 
de que consideren que el mundo, tal cual es, se circunscribe al modo -particular y cultural- en el que se presenta ante sus ojos. "c| De ahí -afirma Montaigne- procede que aquello que se sale de los quicios de la costumbre se crea fuera de los quicios de la razón". ${ }^{10}$

Pero incluso la razón se muestra como algo muy diferente desde esta nueva perspectiva. Ella no se revela ya como una cualidad universal y constante, a partir de la cual los hombres son capaces de juzgar la adecuación o inadecuación de un hábito respecto de la naturaleza, el bien o la virtud. La costumbre tampoco deja indemne a esta facultad que, según lo supone la larga tradición filosófica que hunde sus raíces en la Grecia clásica, distingue y separa a los seres humanos del resto de la naturaleza: “ $b \mid \mathrm{La}$ razón humana es una tintura infusa más o menos en la misma proporción en todas nuestras opiniones y costumbres, sea cual sea su forma: infinita en materia, infinita en diversidad". ${ }^{11} \mathrm{Y}$ en esa ilimitada variabilidad, el entendimiento humano, secundando a la costumbre, se convierte en un instrumento capaz de justificar con igual legitimidad las más disímiles normas legales, por más extravagancia y peculiaridad que estas puedan presentar.

ver lo que se halla bajo sus pies, sin mirar atrás ni adelante; al contrario, recuerdan cosas pasadas para mejor juzgar el presente y prever el porvenir. Son ellos los que, teniendo ya el espíritu bien formado, lo cultivaron también con el estudio y el saber. Cuando la libertad esté completamente perdida y excluida de este mundo, serán ellos quienes la invocarán nuevamente, pues al sentirla con intensidad, al haberla probado y al haber conservado su germen en el espíritu, jamás podrán ser seducidos por la servidumbre, por más que se la disfrace". (Discurso de la servidumbre voluntaria, p.41). Pierre Charron presentará en su Sagesse una idea similar: "[El pueblo] por única regla de verdad, de justicia, o de decoro toma la ley y la costumbre de su país. Cuando se le dice que lo mismo opinan y dicen los de otro lugar, a quienes nuestras costumbres y modales le llaman tanto la atención como las de ellos a nosotros, interrumpe bruscamente a su antojo y dice que son bestias y bárbaros, que equivale siempre a lo mismo. El sabio es mucho más recatado, como veremos, no se apresura a juzgar por temor a exaltarse y causarle daño a su juicio. De hecho hay muchas leyes y costumbres que a primera vista parecen salvajes, inhumanas y contrarias al buen sentido y que, consideradas sin pasión y sanamente y aun no siendo enteramente buenas y justas, por lo menos no carecerán de alguna razón y defensa" (De la sabiduría. II, 8, pp. 328-329).

${ }^{10}$ Los ensayos. I, 22, p. 139.

${ }^{11}$ Los ensayos, I, 22, p. 133. 
$a \mid$ ¿De qué no es capaz en nuestros juicios y creencias? ¿Hay opinión tan extravagante $(. .$.$) hay alguna tan extraña, que la costumbre no la haya$ implantado y establecido por ley en las regiones donde lo ha tenido a bien? (...) $b \mid \mathrm{A}$ mi entender no pasa por la imaginación humana ninguna fantasía tan enloquecida que no se corresponda con el ejemplo de algún uso público, y por consiguiente que nuestra razón no apoye ni fundamente. ${ }^{12}$

Montaigne dedicará el resto del capítulo a constatar esta verdad de los hechos: en primer lugar, realizará un extenso repaso por los ejemplos más diversos y extraordinarios, y su fin no será otro que ilustrar la extrema dificultad que existe para catalogar a cualquiera de estos hábitos como "irracional", o "antinatural". Más tarde, luego de ese repaso, la indagación llegará a su punto más audaz: Montaigne redirigirá su mirada, dejando de lado la enumeración empírica de las costumbres, e interrogándose sobre su origen y fundamento. Ese análisis, a su vez, lo conducirá hacia la siguiente conclusión: el derecho y la ley no tienen su origen ni en el cuerpo del pueblo ni en el cuerpo del rey; ${ }^{13}$ provienen de las costumbres: he allí su único y real fundamento. Las leyes no adquieren su autoridad ni de los decretos divinos, ni de las prescripciones de la madre naturaleza, ${ }^{14}$ ni de los mandatos de ningún gobernante humano. No son leyes porque sean un reflejo especular de la Justicia, o en función de preceptos soberanos legítimos; son leyes en función de sí mismas, es decir, en cuanto cristalizaciones

${ }^{12}$ Los ensayos, I, 22, pp. 131-132.

${ }^{13}$ Sobre la distinción entre los dos cuerpos del rey, uno físico y mortal, y otro simbólico e imperecedero -y por tanto, símbolo de la majestad y del derecho divino a gobernarvéase el excelente y voluminoso trabajo de Ernst Kantorowicz, The King's two bodies. A Study in Mediaeval Political Theology, Princeton, Princeton University Press, 1957.

${ }^{14}$ Una muestra de la crítica montaigneana a la existencia de leyes naturales puede encontrarse en las páginas centrales de su "Apología de Ramón Sibiuda" (II,12). He aquí un breve fragmento: " $a \mid$ Pero son graciosos [los filósofos] cuando, para otorgar alguna certidumbre a las leyes, dicen que hay algunas que son firmes, perpetuas e inmutables, a las que llaman naturales, que están impresas en el género humano por la condición de su propia esencia. Y, éstas, uno dicen que hay tres, otros cuatro, algunos más, otros menos -señal de que se trata de una marca tan dudosa como el resto. Pues son tan desafortunados (...) que de esas tres o cuatro leyes elegidas, no hay ni una sola que no se vea contradicha y desautorizada no por una nación sino por muchas” (Los ensayos, II, 12, p. 874). 
de las opiniones comunes y tradicionales. Y si bien es cierto que las leyes mantienen su crédito por su aparente vínculo con la justicia, esa no es más que una ligazón mistica. ${ }^{15}$

Así, aun reconociendo la fragilidad de ese cimiento, y el extremo peligro que puede implicar el remontar las leyes hasta su origen, Montaigne se dispone a avanzar río arriba. Y al igual que nosotros, tampoco él camina solo; utiliza como brújula uno de los textos más punzantes que hayan visto la luz en la historia de nuestra disciplina: las Hipotiposis Pirrónicas de Sexto Empírico.

\section{Avanzando río arriba}

Escrito durante la segunda mitad del siglo II d.C., ${ }^{16}$ y redescubierto durante el Renacimiento tardío, el texto de las Hipotiposis llegará a manos de Montaigne en la edición latina de $1562 .{ }^{17}$ El ensayista conocerá allí los diversos modos que los pirrónicos utilizaban para contraponer y neutralizar las opiniones y juicios dogmáticos, prestando especial atención al tropo que Sexto Empírico ubica en la décima posición. Éste, "que concierne sobre

\footnotetext{
${ }^{15}$ Como bien se ha señalado, Montaigne "produce una esceptización (historización, relativización) de toda verdad o valor trascendental de la ley", reduciendo el derecho a derecho positivo. Al respecto, véase el excelente análisis de Thomas Berns, "La mystique de la loi: à partir de Montaigne", Revue interdisciplinaire d'études juridiques, 1996, 37, pp. 113-154.

${ }^{16} \mathrm{La}$ fecha es estimativa, pues aunque la vida Sexto Empírico ha sido situada por la mayoría de los estudiosos en ese período, los datos acerca de su existencia real siguen siendo muy controvertidos. En consecuencia, tampoco ninguna de sus obras ha podido hallar un lugar preciso en la cronología de nuestra disciplina.

${ }^{17}$ Luciano Floridi (Sextus Empiricus. The Transmission and Recovery of Pyrrhonism, Oxford, Oxford University Press, 2002) ha mostrado con claridad que las Hipotiposis Pirrónicas no fueron completamente desconocidas durante la Edad Media, e incluso ha hallado al menos tres manuscritos de traducciones latinas datadas en los siglos XIII y XIV. No obstante, aun parece posible afirmar que las potencialidades del compendio de Sexto sólo se revelaron en toda su plenitud luego de la traducción realizada por Henri Estienne en 1562. Cabe recordar que siete años después de aquella primera edición de las Hipotiposis, en 1569, Gentian Hervet realizará la publicación de Adversus Mathematicos, la otra gran obra de Sexto que ha llegado hasta nuestros días.
} 
todo a lo ético", ${ }^{18}$ había sido diseñado por los pirrónicos para poner en cuestión la validez objetiva de "las costumbres, leyes, creencias míticas y opiniones dogmáticas", apelando a la extrema diversidad que es posible hallar en ellas. Presentado por primera vez en el capítulo XIV del libro I, y retomado ampliamente en la segunda mitad del libro III, ${ }^{19}$ este modo conducirá a Sexto a la conclusión de que todas las consideraciones humanas respecto de la bondad, maldad, o indiferencia de las leyes y costumbres no son sino el resultado de una mera convención. Luego de exponer la casi infinita diversidad de usos, reglas de vida y dogmas a las que hombres son afectos, el autor llega a la conclusión de que, "dado que también por este tropo se muestra tamaña divergencia en las cosas, no podemos establecer cuál es la naturaleza del objeto". ${ }^{20}$ Esto es, dada la enorme discrepancia que existe entre aquellos que dicen acomodar sus convicciones a las prescripciones naturales, los pirrónicos arriban a la conclusión contraria a través del siguiente silogismo: si las leyes y las costumbres muestran una profusa diversidad, y el rostro de la naturaleza es presuntamente unánime; luego, las leyes y costumbres de los hombres no poseen un fundamento natural, sino sólo un valor convencional.

Aunque expuesto aquí con suma rapidez, éste será uno de los argumentos que hará mella en Montaigne, quien no sólo tomará nota de la conclusión, sino que también hará un extendido uso del método. Luego de señalar, por un lado, que la costumbre tiene la potencialidad de ejercer su plena autoridad sobre los juicios y las creencias humanas, y por otro, que la razón es un instrumento infinitamente voluble que puede brindar apoyo al más extravagante hábito, el ensayista perfila el camino por el cual habrá de conducirnos hacia el fundamento místico de la ley. Así, echando mano a ese décimo tropo, Montaigne repasará durante varias páginas del capítulo I, 22 una enorme diversidad de usos, leyes y costumbres. He aquí un fragmento del pasaje:

[Hay pueblos] $c \mid$ donde, cuando el rey, para entregarse por entero a la devoción, se retira de su cargo -como sucede a menudo-, su primer heredero es obligado a hacer lo mismo, y el derecho al reino pasa al tercer heredero. Donde se modifica la forma de gobierno según parezcan requerirlo los

\footnotetext{
${ }^{18}$ Sexto Empírico, Hipotiposis Pirrónicas, Madrid, Akal, 1996, I, 145. En adelante, HP.

${ }^{19} \mathrm{HP}, \mathrm{III}, 168-238$.

${ }^{20} \mathrm{HP}, \mathrm{I}, 163$.
} 
asuntos: deponen al rey cuando se estima conveniente y lo sustituyen por ancianos para asumir el gobierno del Estado, y a veces lo dejan también en manos del pueblo. Donde los hombres y mujeres son circuncidados e igualmente bautizados. Donde el soldado que en uno o varios combates ha llegado a presentar al rey siete cabezas de enemigos, es ennoblecido. $b \mid$ Donde viven con la opinión, tan rara e insociable, de mortalidad de las almas...". ${ }^{21}$

De la mano de Sexto, y tomando como fuentes principales de información los diarios de viajeros, ${ }^{22}$ Montaigne hace un repaso por estas leyes y creencias tan ajenas a las prácticas francesas, invitando al lector a ampliar y a profundizar su mirada. Así, en compañía de estos insociables ateos, y de aquellos extravagantes seres que adecuan su forma de gobierno a los avatares de la fortuna, Montaigne va conduciéndonos poco a poco hasta una conclusión tan inevitable como contundente: " $a \mid$ En suma, se me antoja que nada hay que [la costumbre] no logre o que no pueda; y con razón la llama Píndaro, según me han dicho, reina y emperatriz del mundo". ${ }^{23}$ Tanto el autor como el lector se hallan de este modo en inmejorables condiciones para comprender la arbitrariedad y contingencia de su propia cultura, de su propio modo de ser, de su propia ley. El juicio, apoltronado en el trono que los hábitos le han proporcionado y adornado, tambalea ante cada

\footnotetext{
${ }^{21}$ Los ensayos, I, 22, p. 135.

22 Principalmente la Historia General de las Indias (1552) de Francisco López de Gómara, y la Histoire d'un voyage fait en la terre du Brésil (1578) de Jean de Léry. Cabe recordar que Montaigne otorga una enorme importancia a la experiencia del viaje -tanto intelectual como físico- en la formación de todo aquel que desee comprender las características propias de la condición humana, a saber: la variabilidad, la inconstancia, el desatino. En efecto, en su ensayo sobre la formación de los niños, Montaigne afirma enfáticamente la necesidad de formar al discípulo en la escuela de las relaciones humanas: " $a \mid$ Por eso, las relaciones humanas le convienen extraordinariamente [a nuestro discípulo], y la visita de países extranjeros, no sólo para aprender, a la manera de los nobles franceses, cuántos pasos tiene la Santa Rotonda o la riqueza de las enaguas de la Signora Livia o, como otros, hasta qué punto el semblante de Nerón en alguna vieja ruina de allí es más largo o más ancho que el de cierta medalla similar, sino para aprender sobre todo las tendencias y costumbres de esas naciones y para rozar y limar nuestro cerebro con el de otro" (Los ensayos, I, 25, p. 194).

${ }^{23}$ Los ensayos. I, 22, p. 138.
} 
uno de estos contraejemplos, y el mundo se muestra ante los ojos en toda su diversidad. Así, habiéndose librado de "al este violento prejuicio de la costumbre", ${ }^{24}$ logrando desenmascarar las herencias recibidas, el lector atento encuentra que muchas de las cosas que antes admitía de forma indudable tienen como único fundamento el acto de la convención. Un acuerdo ancestral del que nadie tiene memoria, y que ha ganado espesor y solidez gracias a la acción conjunta del tiempo y la costumbre, ocultado tras ese velo de olvido su carácter contingente.

a| Las leyes adquieren su autoridad del dominio y el uso; es peligroso hacerlas remontar a su nacimiento: se engrosan y ennoblecen a medida que avanzan, como nuestros ríos. Si las sigues hacia arriba hasta la fuente, no hay más que un pequeño manantial de agua apenas reconocible, que se enorgullece y fortifica al envejecer. Observa las antiguas consideraciones que dieron el primer impulso a este famoso torrente, lleno de dignidad, horror y reverencia: te parecerán tan ligeras y delicadas que no es extraño que esta gente que todo lo sopesa y refiere a la razón, y que nada admite por autoridad y crédito, tenga con frecuencia sus juicios muy alejados de los juicios públicos. ${ }^{25}$

Así, puede afirmarse que el verdadero motivo de la veneración de las leyes radica tan sólo en el olvido de un origen tan pueril. En tal sentido, el ejercicio filosófico que Montaigne propone conduce al lector (que ya no acepta nada por crédito y autoridad, sino que todo lo sopesa y refiere a la razón) a poner en entredicho la opinión común que atribuye un fundamento natural, metafísico o divino a la autoridad de toda norma, y a reconocer que el único requisito que una ley debe cumplir para gozar de legitimidad es el de ser capaz de perderse en los confines del tiempo, "c| de modo que nadie sepa su origen

${ }^{24}$ Los ensayos. I, 22, p. 141.

${ }^{25}$ Los ensayos, II, 12, pp. 879-880. Tal como lo expresamos más arriba, y tal como se hace patente hacia el final de este pasaje, el ensayista traza una diferencia tajante entre "los juicios públicos" que se ven guiados por el crédito brindado a la autoridad ancestral, y las opiniones de aquellos hombres que refieren toda sus posiciones (intelectuales y políticas) a la sola autoridad de la de la razón. Se vislumbra de este modo la distinción - tan corriente entre los libertinos eruditos del siglo XVII- entre los sabios y el vulgo. Al respecto, véase Pintard, René, Le libertinage érudit dans la primère moitié du XVIIe siècle, Paris, Boivin Editeurs, 1943, 2 vols. 
ni si alguna vez ha sido modificada". ${ }^{26}$ Ahora bien, cuando se hace un recorrido por estas reflexiones no deben olvidarse aquellos elementos que hemos presentado en nuestra sección anterior: la fuerza de la costumbre es tan imperceptible como eficaz, y aun los espíritus más atentos son propensos a caer en las trampas del olvido y la desmemoria. No son sólo los hombres ignorantes los que quedan a merced de repetir por su propia boca los prejuicios que han ingerido con su leche materna, sino que " $a \mid$ todos actuamos así, pues el uso nos hurta el verdadero rostro de las cosas". ${ }^{27}$ Las barricadas con las que la costumbre franquea nuestros senderos de acción y reflexión son innumerables, y se requiere de una extrema y continua atención para evitar la violencia de sus garras: " $a \mid$ Dondequiera que me vuelvo, he de forzar alguna barrera de la costumbre. Hasta tal extremo ha trabado escrupulosamente todos nuestros caminos". 28

Volviendo sobre lo anterior, podemos afirmar que del mismo modo en que la filosofía y la ciencia inventan "elegantes y verosímiles" explicaciones acerca del funcionamiento de la naturaleza, también el derecho se sirve de estas "ficciones legítimas", ${ }^{29}$ cuya función primordial radica en

${ }^{26}$ Los ensayos. I, 43, p.395. Montaigne parafrasea aquí a Platón, quien había afirmado: "Cuando las leyes, en las que [los hombres] se crían, por alguna fortuna divina, llegan a ser inmutables durante un largo período de tiempo, de modo que nadie recuerde ni haya escuchado que alguna vez fueron distintas de lo que son ahora, toda el alma las respeta y teme cambiar algo de lo instituido en ese momento" (Leyes, VII, 798b, en Platón, Diálogos: tomos VIII-IX, Madrid, Gredos, 1999).

${ }^{27}$ Los ensayos, I, 22, p. 140. En efecto, en un pasaje inmediatamente posterior, Montaigne nos relata una experiencia personal con la que ilustra que nadie queda exento de avalar e incurrir en estas prácticas de naturalización. " $a \mid$ En cierta ocasión, tenía que justificar uno de nuestros usos, que se admite con resuelta autoridad a mucha distancia en torno nuestro. Como no quería limitarme a establecerlo, según suele hacerse, por la fuerza de las leyes y los ejemplos, sino indagando sin cesar hasta su origen, encontré su fundamento tan endeble que a punto estuve yo mismo de concebir disgusto por él, yo que había de confirmarlo en otros" (Los ensayos, I, 22, p. 140).

${ }^{28}$ Los ensayos, I, 35, p. 306.

29 " $a \mid$ Las mujeres usan dientes de marfil cuando les faltan los suyos naturales, $y$, en lugar de su verdadera tez, se forman una con alguna materia extraña; se hacen muslos de paño y de fieltro, y se añaden carnes con algodón, y, a la vista y a sabiendas de todos, se embellecen con una belleza falsa y prestada. Eso mismo hace la ciencia $b \mid-\mathrm{y}$ aun nuestro derecho tiene, según dicen, ficciones legítimas 
brindar un sostén duradero a las frágiles, inestables y contingentes comunidades humanas. Las costumbres y las leyes son, en tal sentido, las únicas herramientas de las que los hombres disponen para ponerse a resguardo de las súbitas e impredecibles variaciones a las que se verían sometidos de otro modo, pues el espíritu humano es una capacidad demasiado voluble, y el dejarlo librado a una "licencia desenfrenada" implica correr un enorme -y casi seguro- riesgo de extravío. ${ }^{30}$

No obstante, como hemos intentado dejar en claro a lo largo de toda nuestra reflexión, este peligro no implica en absoluto que las normas legales sean la expresión legítima de una justicia trascendente, o la materialización de la propia naturaleza en el seno de la sociedad. Que los seres humanos sean incapaces de sostenerse sin ellas, las hace útiles, no verdaderas; las hace imprescindibles para el desarrollo de los diversos proyectos vitales -pues de otro modo caerían, seguramente, en un rodar incesante de $\mathrm{duda}^{31}$-, pero

sobre las que funda la verdad de su justicia-. $a \mid$ Nos ofrece como respuesta y nos hace presuponer cosas que ella misma nos enseña que son inventadas" (Los ensayos. II, 12, p. 799).

$30 " a^{2} \mid$ Se le refrena y atenaza mediante religiones, leyes, costumbres, ciencia, preceptos, penas y recompensas mortales e inmortales; aun así, vemos que, por su volubilidad y disolución, escapa a todos esos lazos (...) b| El espíritu es una espada temible para su mismo poseedor si uno no sabe armarse con ella de manera recta y juiciosa. $c \mid$ Y no hay animal al que con mayor justicia haya que poner anteojeras para mantenerle la vista sujeta y fija hacia adelante, y para evitar que se extravíe a un lado u otro fuera de los carriles que el uso y las leyes le trazan. $a \mid$ Por tanto, será mejor que os ciñáis al camino acostumbrado, sea el que fuere, que emprender el vuelo a esta licencia desenfrenada" (Los ensayos. II, 12, p. 837).

${ }^{31}$ Es este temor al desasosiego el que permite a Montaigne justificar su opción por el catolicismo romano frente a la Reforma hugonota, es decir, justificar su permanencia en aquella religión que había heredado junto con las demás leyes: “ $a \mid$ Porque sea cual fuere la verosimilitud de la novedad, no soy dado a cambiar, por mi temor a perder con el cambio. Y puesto que no soy capaz de elegir, asumo la elección ajena y me mantengo en la posición que Dios me ha asignado. Si no lo hiciera así, no podría abstenerme de rodar incesantemente. $a^{2} \mid$ De esta manera, me he mantenido, por la gracia de Dios, íntegro, sin agitación ni turbación de conciencia, en las antiguas creencias de nuestra religión a través de todas las sectas y divisiones que nuestro siglo ha producido" (Los ensayos, II, 12, p. 854). Nótese aquí, asimismo, una clara diferencia entre los escépticos antiguos y los modernos: mientras que los primeros decían alcanzar la imperturbabilidad (ataraxia) luego 
ello no garantiza de ningún modo que las diversas legislaciones mantengan un vínculo privilegiado con la verdad.

b| Ahora bien, las leyes mantienen su crédito no porque sean justas, sino porque son leyes. Éste es el fundamento místico de su autoridad; no tienen otro. $c \mid$ Lo cual les conviene mucho. A menudo están hechas por necios, las más de las veces por gente que, por odio a la igualdad, carece de equidad, pero siempre por hombres, autores vanos e inciertos. Nada es tan grave, extensa y habitualmente falible como las leyes. $b \mid$ Quien las obedezca porque son justas, nos las obedece justamente por el motivo correcto. ${ }^{32}$

Las leyes no son sino una invención humana y, como tal, llevan implícitas en sí mismas las particularidades, indecisiones y vicios propios de quienes les dan origen. ${ }^{33}$ La justicia es tan sólo una prueba más de nuestras flaquezas y necedades, y considerar que en ella se manifiesta la voluntad de un Dios trascendente, de la madre naturaleza, o de un soberano sabio, es equivocar por completo el sentido originario de este entramado al que elementos enfermizos e injustos constituyen en esencia. ${ }^{34}$ Pres-

de contraponer juicios equipolentes (isostheneia) y suspender el juicio (epochè), los segundos parecen no encontrar demasiado sosiego en la indefinición. La imagen de un Descartes hundiéndose en el mar de la duda antes de hallar la luz del cogito, o de un Hume salvado de las garras del escepticismo radical por las noches de amigos y backgammon, son otros ejemplos de este miedo expresado por Montaigne.

${ }^{32}$ Los ensayos. III, 13, pp. 1601-1602. Para un ilustrativo análisis de este pasaje, véase Oyarzún, Pablo, "Sobre el concepto de autoridad", Revista de Humanidades, Chile, Universidad de Chile, 17-18, 2008, pp. 9-34.

${ }^{33}$ En un análisis muy original, André Tournon señala que no fue el contacto con el pirronismo el que llevó a Montaigne a desconfiar de las normas legales, sino su propia experiencia en los tribunales de justicia. Habría sido esa participación en las cámaras judiciales del Parlamento de Burdeos -en las que, recordemos, Montaigne se desempeñó durante diecisiete años- la que habría conducido al ensayista a una consideración escéptica respecto de la creación, interpretación y aplicación de las leyes. Al respecto, véase Tournon, André, "Justice and the law: on the reverse side of the Essays", The Cambridge Companion to Montaigne, Cambridge, Cambridge University Press, 2006, pp. 96-117.

34 “ $b \mid$ Dado que las leyes éticas, que miran al deber particular de cada cual en sí mismo, son tan difíciles de fijar, como vemos que lo son, no es extraordinario que las que gobiernan a tantos particulares lo sean aún más. Examinemos la forma de 
tarles obediencia con motivos de su presunta justicia, y no por la mera autoridad de hallarlas instituidas, es caer en el olvido de esa contingencia originaria, en la trampa que a cada paso nos tiende la costumbre. De este modo, Montaigne remonta el río, revelando y destruyendo al mismo tiempo el fundamento místico de la autoridad de las leyes, a las que no les queda más sustento que la complicidad del tiempo.

\section{Montaigne, entre Pascal y Derrida}

Todas estas reflexiones del ensayista dejarán una marca difícil de disimular en Blaise Pascal, quien en sus Pensamientos (1670) les dedicará una especial atención. Según sugiere allí el matemático, tres serían las posiciones que se habrían asumido a lo largo de la historia en relación a la "esencia de la justicia": según la primera, existe una serie de leyes naturales que, más allá de las diferencias culturales y políticas, conforman un sustrato común a todos los hombres. Quienes defienden esta posición, afirman que "el brillo de la verdadera equidad habría sometido a todos los pueblos", $35 \mathrm{y}$ "confiesan que la justicia no se sustenta en esas costumbres [diversas], sino que reside en las leyes naturales comunes a todo país". ${ }^{36}$ En un segundo grupo se hallan aquellos que sostienen que la justicia sólo se apoya en la autoridad legítima del legislador soberano; para estos, la máxima capital reside en que cada hombre sepa ajustar su comportamiento a las leyes que ha hallado establecidas en su país natal. Por último, un tercer grupo afirma que el único fundamento de la ley radica en "la costumbre del momento, y esto es lo más seguro". ${ }^{37}$ Pascal, aun sin nombrar a Montaigne, toma explicito partido por esta tercera opción, y parafrasea casi textualmente al autor de los Ensayos:

la justicia que nos rige; es una verdadera prueba de la flaqueza humana: hasta tal punto llegan sus contradicciones y sus errores. Lo que nos parece favor y severidad de la justicia, y hay tantas cosas que nos lo parecen que no sé si lo intermedio se encuentra tan a menudo, son partes enfermizas y elementos injustos del cuerpo mismo y de la esencia de la justicia"(Los ensayos, III, 13, p. 1598).

${ }^{35}$ Pascal, Blaise, Pensamientos, Buenos Aires, Altaya, 1993, 60, p.37.

${ }^{36}$ Ibíd., p. 37.

${ }^{37}$ Ibíd., pp. 37-38. 
Nada según la sola razón es justo en sí, todo se tambalea con el tiempo. La costumbre (constituye) toda la equidad, por la sola razón de que ha sido recibida. Ese es el fundamento místico de su autoridad. Quien la remite a su principio, la anula. Nada es tan defectuoso como esas leyes que reparan las faltas. Quien las obedece porque son justas, obedece a la justicia que él imagina, pero no a la esencia de la ley. Esta se halla aglutinada toda en sí misma. Es ley y nada más. Quien quiera examinar el motivo lo encontrará tan débil y tan frágil que, si no está acostumbrado a contemplar los prodigios de la imaginación humana, se admirará de que un siglo le haya prestado tanta reverencia. ${ }^{38}$

Muchos años más tarde, ya en las postrimerías del siglo XX, serán esas mismas consideraciones de Montaigne y Pascal las que servirán a Jacques Derrida como punto de partida para esbozar sus propias reflexiones acerca del origen último de la autoridad de las normas legales. En su ensayo titulado Fuerza de ley (1994), ${ }^{39}$ el francés utilizará ambos textos con el fin de deconstruir las relaciones existentes entre tres conceptos clave en el ámbito de la filosofía política: fuerza, ley y justicia.

En los inicios del texto, Derrida detiene su atención sobre una sentencia crucial respecto de la relación entre esos tres conceptos: «to enforce the lan», la que podría traducirse al castellano como «aplicar la ley». Esta sentencia, afirma el francés - recordando al Kant de la Metafísica de las costumbres ${ }^{40}$ "viene a recordarnos que el derecho es siempre una fuerza

\footnotetext{
${ }^{38}$ Ibíd., p. 38.

${ }^{39}$ Force de loi llevará como sugerente subtítulo Le «Fondament mystique de l'autorité», y estará compuesto de dos partes: la primera, titulada "Del derecho a la Justicia", fue leída como conferencia inaugural de un Coloquio organizado en la Cardozo Law School a fines de 1989, bajo el título Deconstruction and Possibility of Justice, ante un público de filósofos, juristas y teóricos de la literatura; la segunda parte, titulada "Nombre de pila de Benjamin", fue pronunciada en un Coloquio realizado a principios del año siguiente, el 26 de abril de 1990, en la Universidad de California, bajo el título Nazism and the «Final Solution»: Probing the Limits of Representation. Por cuestiones de espacio, y también de relevancia temática (sólo nos interesa mostrar la actualidad de las reflexiones de Montaigne), nuestro breve análisis se circunscribirá a los pasajes iniciales de la primera parte.

${ }^{40}$ Kant, Immanuel, La Metafísica de las Costumbres, traducción de Adela Cortina y Jesús Conill, Tecnos, Madrid, 1989.
} 
autorizada" ${ }^{41}$ es decir, una fuerza que sólo alcanza su justificación mediante su aplicación. El derecho, sin una fuerza que pueda aplicarlo, carece de toda razón de ser. Por tal motivo, se arriba a la conclusión de que la aplicabilidad a través de un medio coactivo no es una característica extrínseca a la ley, sino su complemento necesario ("su predicado esencial"): "La palabra «enforceability» nos remite, pues, a la letra. Nos recuerda literalmente que no hay derecho que no implique en él mismo, a priori, en la estructura analítica de su concepto, la posibilidad de ser «enforced», aplicado por la fuerza". ${ }^{42} \mathrm{Si}$ bien pueden existir leyes que nunca hayan sido puestas en práctica, o a las cuales el paso del tiempo ha tornado vetustas e inaplicables, el concepto mismo de ley implica la aplicabilidad, y la aplicabilidad implica a su vez la existencia de la fuerza, de un medio coactivo, "sea este directo o no, físico o simbólico, exterior o interior, brutal o sutilmente discursivo". ${ }^{43}$

Son esas primeras reflexiones las que conducirán a Derrida hacia aquel terreno que aquí nos resulta relevante, es decir, hacia la consideración de los aportes que todavía hoy pueden hacernos, a este respecto, Pascal y Montaigne. Como dijimos, la atención del francés se detiene en un primer momento sobre la sentencia "to enforce the lan», a través de la cual se pone de manifiesto que, más allá de los vínculos que puedan existir entre la justicia y la ley -o el derecho-, esta última es incapaz de convertirse en justicia de derecho (Gewalt $t^{44}$ ) sin apelar a la fuerza "desde su primer instante, desde su primera palabra". ${ }^{45}$ En ese contexto de reflexión, Derrida refiere a un pensamiento clave de Pascal en torno a la cuestión; un pensamiento que, debido al pernicioso influjo de Montaigne -para quién, como vimos antes, las leyes

\footnotetext{
${ }^{41}$ Derrida, Jacques, Fuerza de ley. El «Fundamento mistico de la autoridad», traducción de Adolfo Barberá y Patricio Peñalver Gómez, Madrid, Tecnos, 1997, p. 15.

${ }^{42}$ Ibíd., p. 16. La cursivas son del original.

${ }^{43}$ Ibíd.,p. 16.

${ }^{44}$ Es precisamente sobre este concepto alemán (Gewalt), que Derrida centrará su atención en la segunda parte de su texto, en donde recuperará las reflexiones de Walter Benjamin en torno a la cuestión de la violencia fundante. Allí señalará, entre otras cosas, que este concepto de Gewalt, traducido usualmente como «violencia», también significa para los alemanes «poder legítimo», «autoridad», «fuerza pública». De este modo, indica el francés, nos encontramos frente a una noción según la cual el poder legítimo y el uso de la fuerza son indistinguibles; una noción, por tanto, que refleja en su semántica un hecho irrevocable.
}

${ }^{45}$ Ibíd., p. 26. 
no son justas en sí mismas, sino porque son leyes-, Antoine Arnauld se tomó la licencia de suprimir en la edición de los Pensées de Port Royal; $;^{46}$ un pensamiento que indica lo siguiente:

Justicia, fuerza. Es justo que se siga lo que es justo; es necesario que se siga lo que es más fuerte.

La justicia sin la fuerza es impotente; la fuerza sin la justicia es tiránica.

La justicia sin fuerza es contradictoria, porque siempre hay malvados. La fuerza sin justicia es acusada. Es preciso, pues, unir la justicia y la fuerza, y para ello hacer que lo es justo sea fuerte o lo que es fuerte sea justo.

La justicia está sujeta a discusión. La fuerza es perfectamente reconocible y sin discusión. Así, no se ha podido dar la fuerza a la justicia, porque la fuerza ha contradicho a la justicia y ha dicho que era injusta, y que ella era la justa. Por tanto, no pudiendo hacer que lo que es justo sea fuerte, se ha hecho que lo que es fuerte sea justo. ${ }^{47}$

En el principio no hay nada más que la fuerza. La fuerza como elemento necesario y constitutivo de la justicia; la fuerza como creadora de derecho; la fuerza -o, por qué no, la violencia- como fundamento último sobre el que sostiene toda la sociedad humana; la fuerza como fundamento místico y olvidado sin el cual las leyes no serían más que un cúmulo de sentencias impotentes.

En haber mostrado esta ligazón, sugiere Derrida, se halla unos de los más relevantes legados de Pascal, quien, a su vez, supo esbozar muchos de sus pensamientos más eclécticos a partir de las reflexiones de Montaigne. En ese sentido, el principal aporte de Montaigne ha radicado, según la mirada de Derrida, en haber trazado una clara distinción entre "las leyes (es decir, el derecho) y la justicia". ${ }^{48}$ En haber mostrado que las leyes no son justas, sino leyes, y que no se las obedece debido a su relación privilegiada con la justicia, sino por el simple hecho de que han sido instituidas con cierta autoridad, acompañadas de la fuerza. En efecto, haciendo referencia a aquel

\footnotetext{
${ }^{46}$ Pensées de M. Pascal sur la religion et sur quelques autres sujets, qui ont esté trouvées après sa mort parmy ses papiers, édition dite de Port-Royal, édition princeps, Paris, Guillaume Desprez, 1670. La edición electrónica de esta obra puede consultarse online en: http:// fr.wikisource.org/

${ }^{47}$ Pensamientos, ed. cit., 103, pp. 46-47.

${ }^{48}$ Derrida, op. cit., p. 29.
} 
último pasaje de los Ensayos que trajimos a colación en el apartado anterior, Derrida afirma que es "la palabra «crédito» la que soporta todo el peso de la proposición y justifica la alusión al carácter «místico» de la autoridad. La autoridad de las leyes sólo reposa sobre el crédito que se les da. Se cree en ellas, ése es su único fundamento. Este acto de fe no es un fundamento ontológico o racional". ${ }^{49}$ Montaigne nos ha hecho ver con toda claridad que las leyes carecen por completo de un fundamento natural, lo que al mismo tiempo -como vimos antes, para impedir aquel peligroso desasosiego de un rodar incesante- exige la institución de un "suplemento de derecho histórico o positivo, es decir, un suplemento de ficción". ${ }^{50}$

Será esta exigencia la que conduzca a Derrida a un pormenorizado análisis del carácter contingente de la ley, y de los inescindibles vínculos que existen entre el poder (es decir, la fuerza y la violencia) y las normas que rigen la existencia humana. ${ }^{51} \mathrm{Y}$ si bien la reconstrucción de esos argumentos excedería en mucho los límites de nuestro trabajo, baste lo señalado hasta aquí como indicación de que la tarea de desmitificación emprendida por Montaigne no sólo hunde sus raíces en el período helenístico, sino que también continúa gozando de muy buena salud por nuestros días.

\section{En el camino de la contingencia}

Hace algunos años, Joan Llinás nos hablaba de la "modernidad y actualidad de Montaigne". ${ }^{52}$ Entre los innumerables argumentos que pueden

\footnotetext{
${ }^{49}$ Ibíd., pp. 29-30.

${ }^{50}$ Ibíd., p. 30.

51 "El surgimiento mismo de la justicia y del derecho, el momento instituyente, fundador y justificador del derecho implica una fuerza realizativa, es decir, implica siempre una fuerza interpretativa y una llamada a la creencia: esta vez no en el sentido de que el derecho estaría al servicio de la fuerza, como un instrumento dócil, servil y por tanto exterior al poder dominante, sino en el sentido de que el derecho tendría una relación más interna y compleja con lo que se llama fuerza, poder o violencia. (Ibíd., p. 32). Otro excelente análisis contemporáneo de esta relación entre la violencia y la ley, y al que Derrida dedica la segunda mitad de su propio ensayo, es el que nos ha legado Walter Benjamin: "Para la crítica de la violencia", Ensayos escogidos. México, Ediciones Coyoacán, 2001, pp. 109-129.

${ }^{52}$ Llinás Begón, Joan, "Modernidad y actualidad de Montaigne", Revista Tópicos, Santa Fe, 2005, 13, pp. 129-143.
} 
destacarse en los Ensayos, Llinás hacía referencia a tres tópicos respecto de los cuales puede ser útil, "en esta época de crisis de la modernidad", volver nuestra mirada sobre los escritos de Montaigne: en primer lugar, el reconocimiento del diálogo como uno de los ejercicios más propios y placenteros a los que puede aspirar el ser humano, lo que podría ser un consejo muy provechoso en momentos en que nuestro mundo multicultural demanda acuerdos y consensos; en segundo, la atenta y profunda reflexión acerca de la identidad personal, la que puede mostrarse incluso como "una tercera vía entre el cartesianismo y sus críticos", es decir, como una camino intermedio entre la concepción del yo como punto arquimédico en la construcción de una edificio de verdades inexpugnables, y una disolución absoluta de la subjetividad en el juego de las interpretaciones. ${ }^{53}$ Por último, en tercer lugar, Llinás destacaba la concepción montaigneana de la filosofía, la cual se encuentra estrechamente ligada al ensayo, esto es, a una práctica de escritura que refleja el derrotero de un pensamiento siempre provisorio, continuamente puesto a prueba. ${ }^{54}$ Modo de concebir la filosofía que resulta sumamente atractivo en una época en el que los grandes sistemas de pensamiento parecen haber perecido. ${ }^{55}$

Retomando estos tres elementos, y ya para concluir, podemos afirmar que lo que hemos intentado mostrar a través de este escrito es que Montaigne quizás también pueda enseñarnos algo interesante respecto a los

${ }^{53}$ En este moi fait de lopins que nos presenta Montaigne encontramos uno de los signos distintivos de las reflexiones contemporáneas, en las que el yo ha dejado de ser concebido como fundamento u origen para pasar a ser entendido como una tarea. Para una consideración más exhaustiva de la cuestión, véase Tizziani, Manuel, El yo hecho de retazos. Identidad y alteridad en los escritos de Michel de Montaigne, Tesina de Licenciatura presentada en la Facultad de Humanidades y Ciencias, UNL, Santa Fe, 2010.

${ }^{54} \mathrm{Al}$ respecto, puede consultarse también el hermoso ensayo de Santiago Kovadloff, "Montaigne no hace pie", Cuadernos Hispanoamericanos, Abril 2004, N 646, pp. 71-76.

${ }^{55}$ En el prólogo a la reciente edición castellana, Antoine Compagnon coincide con este juicio de Llinás: "El momento presente es modesto, reflexivo. Desconfiamos de los sistemas. En Montaigne no los hay: por eso nos reencontramos en él (...) Su actualidad es la de un pensamiento emancipado, deambulante y plural, de un pensamiento sometido a ensayo, enemigo de todos los fanatismos y de todos los fundamentalismos" (Compagnon, Antoine, "Prólogo", Los ensayos, Barcelona, Acantilado, 2007, pp. XXVII-XVIII). 
endebles cimientos sobre los que suelen asentarse muchas de nuestras prácticas sociales más arraigadas. En efecto, si el escenario de la filosofía política contemporánea ha visto emerger figuras de la deconstrucción como Jacques Derrida, o puede ser caracterizado por la irrupción de lo que Oliver Marchart ha denominado el pensamiento político posfundacional, ${ }^{56}$ Montaigne tal vez pueda convertirse en un buen guía para conducirnos por el camino de la contingencia.

Recibido: 3/2014; aceptado: 5/2014

56 Marchart, Oliver, El pensamiento politico posfundacional. La diferencia politica en Nancy, Lefort, Badion y Laclau, Buenos Aires, Fondo de Cultura Económica, 2009, p.14. Según Marchart, el posfundacionalismo - cuyos representantes se muestran como epígonos de Martin Heidegger y Carl Schmitt- ha revelado como una de sus principales tareas de la de realizar "una constante interrogación por las figuras metafísicas fundacionales". Tarea que puede ser caracterizada más ampliamente del siguiente modo: "el enfoque posfundacional no intenta borrar por completo esas figuras del fundamento, sino debilitar su estatus ontológico. El debilitamiento ontológico del fundamento no conduce al supuesto de la ausencia total de todos los fundamentos, pero sí a suponer la imposibilidad del fundamento último, lo cual es algo enteramente distinto, pues implica la creciente conciencia, por un lado, de la contingencia y, por otro, de lo político como el momento de un fundar parcial y, en definitiva, siempre fallido" (pp. 14-15). 